\title{
IDEAS ABOUT MARRIAGE DEPENDING ON THE STRUCTURE OF VALUABLE ORIENTATIONS OF WOMEN IN EARLY ADULTHOOD
}

\author{
Svetlana Merzlyakova ${ }^{1}, \&$ Marina Golubeva ${ }^{2}$ \\ ${ }^{1}$ Chair of General and Cognitive Psychology, Astrakhan State University (Russia) \\ ${ }^{2}$ Chair of English Language for Humanitarian Specialties, Astrakhan State University (Russia)
}

\begin{abstract}
The phenomenon of marriage is one of the little-studied questions of family psychology. The resolution of the contradiction between the need of modern society to form complete and adequate ideas about the marital role among students and the need to identify socio-psychological factors that influence the development of ideas about marriage determines the problem of research.

The purpose of the study is to identify the features of ideas about marriage (Ideal husband, Ideal wife) depending on the structure of valuable orientations of young women in early adulthood.

Methods of research. Theoretical and methodological literature analysis, questionnaire, psycho-diagnostic methods (the questionnaire "A Value and Availability Ratio in Various Vital Spheres Technique" by E.B. Fantalova, the method of Semantic Differential, developed by Charles E. Osgood, projective technique of "Incomplete Sentences", the questionnaire "Role Expectations and Claims in Marriage" by A. N. Volkova); mathematical and statistical data processing methods. During the analytical stage we used mathematical and statistical methods that allowed us to establish the reliability of the research results. All calculations were performed using the IBM SPSS Statistics 21 computer program. The analysis included descriptive statistics, cluster analysis (K-means method), Kolmogorov-Smirnov test for one sample, Shapiro-Wilkes criterion, and correlation analysis.

The study involved 310 female students in age from 20 to 22 from Astrakhan State University and the Astrakhan Branch of the Russian Presidential Academy of National Economy and Public Administration. It was found that among young female students 45 people $(14.5 \%)$ are focused on the values of professional self-realization, 59 people (19\%) are focused on gnostic and aesthetic values, and 206 people $(66.5 \%)$ are focused on the values of personal happiness.

The results showed that the concepts of marriage have both common features and specific features due to the influence of the structure of valuable orientations of the respondents. Ideas about marriage are characterized by fragmentary formation of emotional and behavioral components, in some cases the presence of cognitive distortions. The obtained results actualize the importance and necessity of psychological and pedagogical support of the process of family self-determination of students, the formation of complete and adequate ideas about marriage in the conditions of the educational environment of the university.
\end{abstract}

Keywords: Ideas about marriage, valuable orientations.

\section{Introduction}

Demographic and social problems of modern family are largely related to the complexity of performing marital and parental roles by young people. E. I. Zakharova analyzes the function of representations about the content of such social roles as spouse and parent from the positions of P. Ya. Galperin's teaching about orientation (Zakharova, 2012). When starting to develop a new field of activity a person relies on the specific ideas he has about the nature of its implementation. Ideas about the social role (spouse, parent) are formed long before he begins to master it ("latent learning") and perform an orienting function (Zakharova, Karabanova, Starostina, \& Dolgikh, 2019).

The phenomenon of marriage is one of the little-studied questions of family psychology. Relying on P. Ya. Galperin, O. A. Karabanova, E. I. Zakharova's ideas we consider the concept of marriage as a reference point, based on which a person will build their marital behavior in the future. The structure of ideas about marriage includes cognitive, emotional, and behavioral components. The cognitive component is the image of oneself as a spouse and marriage partner, knowledge and understanding of 
marital functions, awareness of the qualities necessary for mastering marital functions and implementing marital behavior. The emotional component is a positive attitude towards the family, marriage partner, future children, marital rights and responsibilities, and the need for a family lifestyle. The behavioral component is awareness of the ways to implement marital functions, role expectations (setting for the active performance of family duties by the marriage partner) and role claims (readiness and ability to perform family duties). The resolution of the contradiction between the need of modern society to form complete and adequate ideas about the marital role among students and the need to identify socio-psychological factors that influence the development of ideas about marriage determines the problem of research.

\section{Objectives}

The purpose of the study is to identify the features of ideas about marriage (Ideal husband, Ideal wife) depending on the structure of valuable orientations of young women in early adulthood.

\section{Methods}

To diagnose the structure of valuable orientations we used the questionnaire "A Value and Availability Ratio in Various Vital Spheres Technique" by E. B. Fantalova (2001). To identify the content characteristics in the representations of marriage we used the following psych diagnostic methods: The Method of Semantic Differential, developed by Charles E. Osgood (Solomin, 2001), Projective Technique of "Incomplete Sentences" (Raigorodsky, 2001), the questionnaire "Role Expectations and Claims in Marriage" by A. N. Volkova (Volkova \& Trapeznikova, 2012). Using a modified version of the semantic differential method we determined the value attitude of female students towards such concepts as "Ideal husband", "Ideal wife". In addition, they established the significance of such personal qualities as performance of duties, care, personal independence, responsibility, sexuality, patience, hard work, respect for another person, balance, success, empathy which formed the content of the cognitive component of ideas about marriage. The "Incomplete Sentences" Projective Technique allowed us to study the elements of the emotional component of ideas about marriage: the relationship to the family as a social institution, one's own family, the future marriage partner, oneself, future children, romantic love, sex, family conflicts, divorce, primacy and responsibility in the family, the rights and duties of spouses, family recreation and leisure. Using the questionnaire "Role Expectations and Claims in Marriage" by A. N. Volkova we have identified the installation of youths to actively fulfill future marriage partner family roles (role expectations) and their own personal commitment to family responsibilities in the household, parental educational, emotional and psychotherapeutic spheres of social activity, visual appeal (role claim) which was the behavioral component views about marriage.

During the analytical stage we used mathematical and statistical methods that allowed us to establish the reliability of the research results. All calculations were performed using the IBM SPSS Statistics 21 computer program. The analysis included descriptive statistics, cluster analysis (K-means method), Kolmogorov-Smirnov test for one sample, Shapiro-Wilkes criterion, and correlation analysis.

The study involved 310 female students in age from 20 to 22 from Astrakhan State University and the Astrakhan Branch of the Russian Presidential Academy of National Economy and Public Administration. All respondents were informed about the study and agreed to participate. We reported on the topic, stressed the confidentiality of the research and the voluntary participation of students and stayed in the audience to answer any questions.

\section{Discussion}

Using the questionnaire "A Value and Availability Ratio in Various Vital Spheres Technique" by E. B. Fantalova we determined the hierarchy of values of students. As a result of divisive clustering of the empirical sample there were identified three homogeneous clusters. In the age group of early adulthood 45 people $(14.5 \%)$ were identified with an orientation to the values of professional self-realization, 59 people $(19 \%)$ with an orientation to gnostic and aesthetic values, and 206 people $(66.5 \%)$ with an orientation to the values of personal happiness.

Further, using correlation analysis we identified the content characteristics of ideas about marriage depending on the structure of valuable orientations of young women. For this purpose, we calculated the correlation coefficients between a particular image (Ideal husband, Ideal wife) and elements of the cognitive, emotional and behavioral components. For quantitative variables whose distribution corresponds to the normal law (established by calculating the Kolmogorov-Smirnov test for 
one sample, the Shapiro-Wilkes test) we calculated the Pearson linear correlation coefficient (r). For ordinal variables and quantitative variables whose distribution significantly differs from the normal law, the Spearman rank correlation coefficient $\left(r_{s}\right)$ is used. For final conclusions we used results at the level of statistical significance $\mathrm{p} \leq 0.05 ; \mathrm{p} \leq 0.01$. The procedure of ranking by the value of the correlation coefficient allowed us to determine the hierarchy of content characteristics in representations of marriage from the most important to the least significant.

The objective dependence of ideas about marriage on the formed structure of valuable orientations among young women in early adulthood (from 20 to 22 years) is established. Table. 1. presents the results of a correlation analysis of ideas about marriage depending on the structure of valuable orientations of young women aged 20 to 22 years.

Table 1. Research of features of representations about Ideal husband depending on the structure of valuable orientations of female students aged from 20 to 22 years.

\begin{tabular}{|c|c|c|c|}
\hline Content characteristics & $\begin{array}{l}\text { Orientation on } \\
\text { the values of } \\
\text { professional } \\
\text { self-realization }\end{array}$ & $\begin{array}{l}\text { Orientation to } \\
\text { gnostic and } \\
\text { aesthetic values }\end{array}$ & $\begin{array}{l}\text { Orientation on } \\
\text { the values of } \\
\text { personal life }\end{array}$ \\
\hline My father & $\mathrm{r}_{\mathrm{s}}=0,079$ & $\mathrm{r}=0,250$ & $r_{s}=0,378^{* *}$ \\
\hline Performance of duties & $r_{s}=0,319^{*}(8)$ & $r=0,373^{* *}(7)$ & $r_{s}=0,257^{* * *}(11)$ \\
\hline Caring & $r_{s}=0,413^{* *}(5)$ & $r=0,631^{* *}(1)$ & $r_{s}=0,587^{* *}(1)$ \\
\hline Personal independence & $r_{s}=0,476^{* * *}(2)$ & $r=0,418^{* * *}(6)$ & $r_{s}=0,453^{* *}(4)$ \\
\hline Responsibility & $r_{s}=0,317^{*}(9)$ & $\mathrm{r}=0,238$ & $r_{s}=0,358^{* * *}(6)$ \\
\hline Sexuality & $r_{s}=0,449^{* * *}(3)$ & $r=0,537^{* * *}(3)$ & $r_{s}=0,458^{* *}(3)$ \\
\hline Patience & $r_{s}=0,397^{* *}(7)$ & $r=0,308^{*}(9)$ & $r_{s}=0,339^{* *}(8)$ \\
\hline Industriousness & $r_{s}=0,499^{* *}(1)$ & $r=0,497^{* * *}(4)$ & $r_{s}=0,340^{* *}(7)$ \\
\hline Respect for other people & $r_{s}=0,403^{* *}(6)$ & $r=0,593^{* *}(2)$ & $r_{s}=0,479^{* *}(2)$ \\
\hline Balance & $\mathrm{r}_{\mathrm{s}}=0,262$ & $r=0,262^{*}(10)$ & $r_{s}=0,408^{* * *}(5)$ \\
\hline Successfulness & $r_{s}=0,425^{* *}(4)$ & $r=0,343^{* *}(8)$ & $r_{s}=0,358^{* *}(6)$ \\
\hline Empathy & $r_{s}=0,276$ & $r=0,421^{* *}(5)$ & $r_{s}=0,216^{* *}(13)$ \\
\hline Attitude towards family as a social institution & $\mathrm{r}_{\mathrm{s}}=0,163$ & $r_{\mathrm{s}}=-0,129$ & $r_{s}=0,209^{* * *}(14)$ \\
\hline Attitude towards one's own family & $r_{\mathrm{s}}=-0,005$ & $r_{\mathrm{s}}=-0,070$ & $r_{s}=0,263^{* *}(10)$ \\
\hline Attitude towards future marriage partner & $\mathrm{r}_{\mathrm{s}}=0,252$ & $\mathrm{r}_{\mathrm{s}}=0,042$ & $r_{s}=0,180^{*}(15)$ \\
\hline Attitude towards oneself & $\mathrm{r}_{\mathrm{s}}=0,016$ & $\mathrm{r}_{\mathrm{s}}=0,103$ & $r_{s}=0,117$ \\
\hline Attitude towards future children & $\mathrm{r}_{\mathrm{s}}=-0,102$ & $\mathrm{r}_{\mathrm{s}}=-0,118$ & $r_{\mathrm{s}}=0,084$ \\
\hline Attitude towards love of the romantic type & $\mathrm{r}_{\mathrm{s}}=0,037$ & $\mathrm{r}_{\mathrm{s}}=0,109$ & $r_{s}=0,236^{* *}(12)$ \\
\hline Attitude towards sex & $r_{s}=-0,109$ & $\mathrm{r}_{\mathrm{s}}=0,099$ & $r_{s}=-0,003$ \\
\hline Attitude towards divorce & $r_{s}=-0,125$ & $\mathrm{r}_{\mathrm{s}}=0,004$ & $r_{s}=-0,008$ \\
\hline Attitude towards conflicts & $\begin{array}{c}r_{s}=-0,354^{*} \\
(10)\end{array}$ & $r_{s}=-0,046$ & $r_{s}=-0,028$ \\
\hline Leadership and responsibility in the family & $r_{s}=0,046$ & $r_{s}=-0,169$ & $r_{s}=0,015$ \\
\hline Rights and obligations of spouses & $r_{s}=0,290$ & $\mathrm{r}_{\mathrm{s}}=0,119$ & $r_{s}=0,049$ \\
\hline $\begin{array}{l}\text { Attitude towards family recreation and } \\
\text { leisure }\end{array}$ & $\mathrm{r}_{\mathrm{s}}=0,020$ & $r_{s}=-0,103$ & $\mathrm{r}_{\mathrm{s}}=0,033$ \\
\hline Intimately sexual scale & $r_{s}=0,100$ & $\mathrm{r}=0,037$ & $r_{s}=-0,049$ \\
\hline Personal identification with your spouse & $\mathrm{r}_{\mathrm{s}}=0,249$ & $\mathrm{r}=0,298$ & $r_{s}=-0,020$ \\
\hline Household sphere (role expectations) & $r_{s}=-0,034$ & $\mathrm{r}=0,345$ & $r_{s}=-0,217$ \\
\hline Parent-educational sphere (role expectations) & $\mathrm{r}_{\mathrm{s}}=0,110$ & $\mathrm{r}=0,072$ & $r_{s}=-0,116$ \\
\hline Social activity (role expectations) & $r_{s}=0,168$ & $\mathrm{r}=0,092$ & $\mathrm{r}_{\mathrm{s}}=0,010$ \\
\hline $\begin{array}{l}\text { Emotional and psychotherapeutic sphere } \\
\text { (role expectations) }\end{array}$ & $\mathrm{r}_{\mathrm{s}}=0,132$ & $\mathrm{r}_{\mathrm{s}}=0,256$ & $\mathrm{r}_{\mathrm{s}}=0,177$ \\
\hline External attractiveness (role expectations) & $r_{s}=0,240$ & $\mathrm{r}=0,191$ & $r_{s}=0,325^{* *}(9)$ \\
\hline
\end{tabular}

Notes: * - correlation is significant at $0.05, * *$ - correlation is significant at 0.01

The image "Ideal husband" is characterized by a fullness of the elements of the cognitive component, a weak representation of the emotional and behavioral components. Common personal qualities in the image "Ideal husband" are caring, sexuality, respect for other people, personal independence, industriousness, successfulness, patience, and performance of duties. In early adulthood the image "Ideal husband" increases the importance of personal independence, sexuality, and patience. 
The image "Ideal husband" for young women who are focused on the values of professional self-realization acquires more masculine features is supplemented by responsibility, a negative attitude towards family conflicts. In early adulthood young women focused on gnostic and aesthetic values the image "Ideal husband" includes such qualities as balance, empathy. The image "Ideal husband" for young women who are focused on the values of personal life is supplemented with elements of cognitive (responsibility, balance, empathy), emotional (positive attitude towards family as a social institution, towards their own family, towards the future marriage partner, towards love of the romantic type), behavioral (external attractiveness) components. The image of their own father is a guide in the formation of ideas about ideal husband only for young women who are focused on the values of personal life.

An invariant characteristic of the image "Ideal wife" among young women in early adulthood is the formation of the cognitive component of ideas about the marital role (Table. 2).

Table 2. Research of features of representations about Ideal wife depending on the structure of valuable orientations of female students aged from 20 to 22 years.

\begin{tabular}{|c|c|c|c|}
\hline Content characteristics & $\begin{array}{l}\text { Orientation on } \\
\text { the values of } \\
\text { professional } \\
\text { self-realization }\end{array}$ & $\begin{array}{l}\text { Orientation to } \\
\text { gnostic and } \\
\text { aesthetic values }\end{array}$ & $\begin{array}{l}\text { Orientation on } \\
\text { the values of } \\
\text { personal life }\end{array}$ \\
\hline My mother & $r_{s}=0,325^{*}$ & $r=0,466^{* *}$ & $r_{s}=0,430^{* *}$ \\
\hline Performance of duties & $r_{s}=0,396^{* *}(7)$ & $r=0,471^{* *}(8)$ & $r_{s}=0,354^{* *}(11)$ \\
\hline Caring & $r_{s}=0,661^{* *}(1)$ & $r=0,712^{* *}(2)$ & $r_{s}=0,597^{* *}(1)$ \\
\hline Personal independence & $r_{s}=0,562^{* *}(4)$ & $r=0,530^{* *}(4)$ & $r_{s}=0,530^{* *}(3)$ \\
\hline Responsibility & $r_{s}=0,323^{*}(11)$ & $r=0,366^{* *}(10)$ & $r_{s}=0,377^{* *}(10)$ \\
\hline Sexuality & $r_{s}=0,469^{* *}(5)$ & $r=0,490^{* *}(6)$ & $r_{s}=0,496^{* * *}(4)$ \\
\hline Patience & $r_{s}=0,444^{* * *}(6)$ & $r=0,278^{*}(11)$ & $r_{s}=0,392^{* *}(7)$ \\
\hline Industriousness & $r_{s}=0,573^{* *}(3)$ & $r=0,719^{* * *}(1)$ & $r_{s}=0,459^{* *}(5)$ \\
\hline Respect for other people & $r_{s}=0,611^{* *}(2)$ & $r=0,614^{* *}(3)$ & $r_{s}=0,551^{* *}(2)$ \\
\hline Balance & $r_{s}=0,339^{*}(9)$ & $r=0,376^{* *}(9)$ & $r_{s}=0,386^{* *}(8)$ \\
\hline Successfulness & $r_{s}=0,338^{*}(10)$ & $r=0,485^{* *}(7)$ & $r_{s}=0,404^{* *}(6)$ \\
\hline Empathy & $r_{s}=0,358^{*}(8)$ & $r=0,501^{* *}(5)$ & $r_{s}=0,384^{* * *}(9)$ \\
\hline $\begin{array}{l}\text { Attitude towards family as a social } \\
\text { institution }\end{array}$ & $r_{s}=0,046$ & $\begin{array}{c}r_{s}=-0,302^{*} \\
(12)\end{array}$ & $r_{s}=0,222^{* *}(14)$ \\
\hline Attitude towards one's own family & $\mathrm{r}_{\mathrm{s}}=0,001$ & $r_{\mathrm{s}}=-0,096$ & $r_{s}=0,184^{*}(17)$ \\
\hline Attitude towards future marriage partner & $\mathrm{r}_{\mathrm{s}}=0,077$ & $\mathrm{r}_{\mathrm{s}}=0,001$ & $r_{s}=0,217^{* *}(15)$ \\
\hline Attitude towards oneself & $\mathrm{r}_{\mathrm{s}}=0,082$ & $r_{s}=-0,006$ & $\mathrm{r}_{\mathrm{s}}=0,131$ \\
\hline Attitude towards future children & $\mathrm{r}_{\mathrm{s}}=-0,162$ & $\mathrm{r}_{\mathrm{s}}=-0,009$ & $r_{\mathrm{s}}=0,058$ \\
\hline Attitude towards love of the romantic type & $\mathrm{r}_{\mathrm{s}}=-0,171$ & $\mathrm{r}_{\mathrm{s}}=0,016$ & $r_{s}=0,272^{* *}(12)$ \\
\hline Attitude towards sex & $\mathrm{r}_{\mathrm{s}}=-0,142$ & $\mathrm{r}_{\mathrm{s}}=-0,125$ & $r_{s}=0,047$ \\
\hline Attitude towards divorce & $\mathrm{r}_{\mathrm{s}}=0,024$ & $r_{s}=-0,012$ & $r_{\mathrm{s}}=-0,097$ \\
\hline Attitude towards conflicts & $r_{s}=-0,034$ & $r_{s}=-0,020$ & $r_{s}=-0,163^{*}(18)$ \\
\hline Leadership and responsibility in the family & $\mathrm{r}_{\mathrm{s}}=-0,181$ & $\mathrm{r}_{\mathrm{s}}=-0,137$ & $\mathrm{r}_{\mathrm{s}}=0,103$ \\
\hline Rights and obligations of spouses & $\mathrm{r}_{\mathrm{s}}=0,156$ & $\mathrm{r}_{\mathrm{s}}=0,219$ & $\mathrm{r}_{\mathrm{s}}=0,134$ \\
\hline $\begin{array}{l}\text { Attitude towards family recreation and } \\
\text { leisure }\end{array}$ & $r_{s}=-0,220$ & $r_{s}=-0,125$ & $r_{s}=0,203^{*}(16)$ \\
\hline Intimately sexual scale & $\mathrm{r}_{\mathrm{s}}=0,073$ & $\mathrm{r}=-0,358$ & $\mathrm{r}_{\mathrm{s}}=0,126$ \\
\hline Personal identification with your spouse & $\mathrm{r}_{\mathrm{s}}=0,039$ & $\mathrm{r}=-0,084$ & $\mathrm{r}_{\mathrm{s}}=0,182$ \\
\hline Household sphere (role claims) & $\mathrm{r}_{\mathrm{s}}=0,236$ & $r=-0,138$ & $\mathrm{r}_{\mathrm{s}}=0,099$ \\
\hline Parent-educational sphere (role claims) & $\mathrm{r}_{\mathrm{s}}=0,173$ & $\begin{array}{c}r=-0,505^{* *} \\
(13)\end{array}$ & $\mathrm{r}_{\mathrm{s}}=0,050$ \\
\hline Social activity (role claims) & $\mathrm{r}_{\mathrm{s}}=0,027$ & $\mathrm{r}=0,177$ & $\mathrm{r}_{\mathrm{s}}=0,014$ \\
\hline $\begin{array}{l}\text { Emotional and psychotherapeutic sphere } \\
\text { (role claims) }\end{array}$ & $\mathrm{r}_{\mathrm{s}}=0,267$ & $\mathrm{r}=0,103$ & $\mathrm{r}_{\mathrm{s}}=0,255$ \\
\hline External attractiveness (role claims) & $\mathrm{r}_{\mathrm{s}}=-0,120$ & $\mathrm{r}=-0,014$ & $0,268^{* *}(13)$ \\
\hline
\end{tabular}

Notes: $*$ - correlation is significant at $0.05, * *$ - correlation is significant at 0.01 
Common personal qualities in the image "Ideal wife" are: caring, respect for other people, industriousness, personal independence, sexuality, empathy, successfulness, patience, balance, performance of duties, responsibility. Among young women's ideas about ideal wife the importance of respect for other people, sexuality, and empathy increases. When developing ideas about ideal wife young women continue to focus on the image of their own mother. The image "Ideal wife" among young women who are focused on gnostic and aesthetic values is characterized by the presence of cognitive distortions which are manifested in a negative attitude towards family as a social institution, the low importance of parental and educational functions and the role of the mother. Young women who are focused on the values of personal life in the image "Ideal wife" there are additional elements of emotional (positive attitude towards family as a social institution, towards their own family, towards the future marriage partner, towards romantic love, towards family recreation and leisure, negative attitude towards family conflicts) and behavioral components (external attractiveness).

\section{Conclusions}

So, the structure of valuable orientations is a personal factor that determines the specifics of ideas about marriage among young women in early adulthood. The dynamics of ideas about marriage is characterized by heterochronous formation of cognitive, emotional and behavioral components. Ideas about the social role of the spouse (Ideal husband, Ideal wife) are considered as reference points based on which young women will build their own marital behavior in the future. The concepts of marriage have both common features and specific features due to the influence of the structure of valuable orientations. Due to the lack of purposeful work on formation of the younger generation readiness for marital views about marriage are characterized by fragmentation of formation of emotional and behavioral component, in some cases, the presence of cognitive distortion (the image "Ideal wife" young women with a focus on the gnostic and aesthetic value in early adulthood).

\section{Acknowledgments}

The reported study was funded by RFBR, project number 20-013-00072.

\section{References}

Fantalova, E. B. (2001). Diagnostics and psychotherapy of internal conflict. Samara.

Raigorodsky, D. Ya. (Ed. and compiler). (2001). Practical Psych Diagnostics. Methods and Tests. Tutorial. Samara: Publishing House "BAKHRAKH-M".

Solomin, I. L. (2001). Psychosemantic diagnosis of hidden motivation. Methodical manual. SPb.: IMATON.

Volkova, A. N., \& Trapeznikova, T. M. (2012). Methodical Receptions of Diagnostics of Matrimonial Relations. Questions of psychology, 5, 110-116.

Zakharova, E. I. (2012). Individual Notions of Social Role Characteristics as Means of Orientation. Cultural-historical Psychology, 4, 38-41.

Zakharova, E. I., \& Karabanova, O. A., \& Starostina, Y.A., \& Dolgikh, A. G. (2019). Ideas about the Future of Parenthood in Adolescence and Young Adulthood. Russian Psychological Journal, 2 (16), 103-122. 